\title{
TRANSITION SIGNALS USED IN SHORT STORIES
}

\author{
Sahlan Tampubolon \\ University of HKBP Nommensen \\ email: sahlantampubolon@ymail.com
}

\begin{abstract}
The purpose of this study is to find out types and the dominant one of transition signals used in short stories. Research method used in this study is descriptive qualitative by doing library research. The data were collected by analyzing the transition signal used infive short stories. The results shows that the transition signals used in short stories are the transition signal indicates time, comparison, additional idea, and contrast. The dominant transition signal used is the transition signal indicates additional idea. The findings shows that the transition signal used on the five short stories is developed in a single central theme.
\end{abstract}

Key words: Transition signals, Short stories, Central theme

\section{Introduction}

Transition signal is defined as a bridge to link the ideas, it makes the idea hold together, the ideas that is going to convey cannot be accepted if there is no bridge which relates each idea to other, it shows that how important transition signal in building the ideas (Vincent: 1984). The absence of holding together ideas in writing is the reason why the writer chooses the title of this paper. Transition signals are connecting words or phrases that act like bridges between parts of the writing, they link the sentences and paragraphs together smoothly so that there are no abrupt jumps or breaks between ideas. There are four basic groups of transition signals according to the connecting forms, sentence connector, coordinator, subordinator, and preposition and determiner.

Transition signals are useful in achieving good cohesion and coherence in your writing. This page gives information on what transition signals are, the grammar of transition signals, and different types of transition signals. There is also an example essay at the end in which you can highlight the different types of transition signal, as well as some exercises to help you practice this area.

Language is one of the of the human behavior aspect in life that involves the use of vocal sounds in meaningful patterns, and when they exist, corresponding written symbols to form, express, and communicate thoughts and feelings. Language is any system of signs, movements, etc, used to express meanings or feelings, particular style or manner of expression (Procter 1981:617).

There are some forms of language, it can be signs, symbols, gesture, use of vocal sound, and also in written form. Conveying language in written form also can be used indirectly, that is just writing down all thoughts or feelings in a piece of paper without getting face to face, so that many people think that this communication form is not so difficult. There are many aspects in writing that need to pay attention carefully. The first thing that you have to think it over is how you should write your idea so that your reader can understand what you mean, how do you arrange your writing related to each 
other so that it is hold together and form a unity idea.

By doing this analysis,it is proven that the transition signals hold the most important role in linking the ideas. In this study the writer uses the short stories as the object of analysis because short story is a very interesting reading material which often to be chosen by many people. The contents of short story are also more interested because usually they give certain experiences that can touch one's feeling so that can be understood more easily.

In doing this study the writer could not apart from the problems. There are some problems appear from this study. Those problems would guide the writer in finishing this study. It can be formulated as follows: 1 . What types of transition signals are used in short stories? 2. What is the dominant type of transition signal found in short stories?

This study focuses in analyzing the Transition Signals used in short stories. The purposes of this paper are: 1 . To find out the types of transition signals used in short stories. 2. To find out the dominant types of transition signal used in short stories.

\section{Transition signals}

This page gives information on what transition signals are, the grammar of transition signals, and different types of transition signals.Tampubolon (2014:3) elucidated that thewrong placementofthewordsin the sentenceswillmake the sentence sound awkward, ridiculous orconfusing.Thewriter also need to watch the placementof modifiers such as almost, even, hardly, nearly, often, and only. There is also an example essay at the end in which you can highlight the different types of transition signal, as well as some exercises to help you practice this area. Oshima, A \& Hogue, A 1991 elucidated that transition signals are connecting words or phrases that act like bridges between parts of your writing. They link your sentences and paragraphs together smoothly so that there are no abrupt jumps or breaks between ideas. Transition signals act like signposts to indicate to the reader the order and flow of your writing and ideas. They strengthen the internal cohesion of your writing. Using transitions makes it easier for the reader to follow your ideas. They help carry over a thought from one sentence to another, from one paragraph to another, or from one idea to another.

When write an essay, it is needed to make a list of ideas one after another to help the readers know how the ideas are related, we use certain words that connect one thought to the next. These words are called transition words since they create the transition, or bridge between sentences (Smoke 1987:173). According to Mandell (1985:114), transition signals are the words and phrases show the relationship of one sentence or clause to another. These signals speed up your reader's understanding and tie together ideas before your reader has a chance to forget them. Besides that Mandell (1989:81) states that transition signals are words and phrases; but, similarly, also, on the other hand, moreover, in contrast, the same as, therefore, however, and so on, aid coherence by indicating the relationship among sentences. By establishing these connections, transition words and phrases tie together ideas in paragraph.

Moreover Vincent (1984:166). states that transition signal is a signal word indicates the presence of a premise or conclusion. Transition signals are words indicating exactly how a statement in one sentence relates to the statement it follows On the other hand Frank (1983:57) defines that the word transition, which means "go over" or "go across", refers to the smooth connection between paragraphs. Transition acts as a bridge between the general content of the main part of the composition. Next, McMurrey (1983:178) states that transition signal is like glue. It glues pieces of the paragraph fit together into solid. Based on those definitions above the writer 
concludes that transition signal is the words and phrases which have a function as a bridge or glue for tying each sentence to be together, so that the ideas in writing to be related and unity.

There are several types of transition signals.Harbrace (1968: 97). Some lead your reader forward and imply the building of an idea or thought, while others make your reader compare ideas or draw conclusions from the preceding thoughts. Broadly speaking, transition signals can be divided into three types, they are: sentence connectors, clause connectors, other connectors.Oshima (1991) again defined thatSentence connectors are used to connect two sentences together. They are joined by a full-stop (period) or semi-colon, and are followed by a comma. The following are examples of sentence connectors. Transition signals are very useful. However, they should not be used to begin every sentence. Transition signals are very useful; however, they should not be used to begin every sentence. Contrast signals are one type of transition signals. In addition, there are others such as compare signals and addition signals. Clause connectors are used to connect two clauses together to form one sentence. They are joined by a comma. The following are examples of clause connectors. Transition signals are very useful, but they should not be used to begin every sentence. Although transition signals are very useful, they should not be used to begin every sentence. Contrast signals are one type of transition signal, and there are others such as compare signals and addition signals.

Other

connectors follow different grammar patterns. Many are followed by noun phrases. Some are verbs and should therefore be used as verbs in a sentence. The following are examples of other connectors. Despite their importance in achieving cohesion, transition signals should not be used to begin every sentence. Good cohesion is the result of using repeated words, reference words, and transition signals. It is clear that careful use of transition signals will improve the cohesion in your writing. Contrast signals are one type of transition signal. Another type is comparison signals.

Below are examples of different types of transition signals. They are divided by type, and sub-divided according to grammar.

Table 1. Types of Transition Signals

\begin{tabular}{|c|c|c|}
\hline $\begin{array}{l}\text { Types of } \\
\text { transition } \\
\text { Signals }\end{array}$ & $\begin{array}{l}\text { Sub } \\
\text { Type }\end{array}$ & Examples \\
\hline $\begin{array}{c}\text { To introduce } \\
\text { an additional idea }\end{array}$ & $\begin{array}{l}\text { Sentence connectors } \\
\text { Clause connectors } \\
\text { Other }\end{array}$ & $\begin{array}{l}\text { Also, besides, furthermore, in } \\
\text { addition, moreover, additionally. } \\
\text { And, nor } \\
\text { another (+ noun), } \\
\text { an additional (+ noun) }\end{array}$ \\
\hline To compare & $\begin{array}{l}\text { Sentence connectors } \\
\text { Clause connectors }\end{array}$ & $\begin{array}{l}\text { Likewise, similarly, equally } \\
\text { in the same way. } \\
\text { And, both... and, not only... but also, } \\
\text { neither... nor, just as. }\end{array}$ \\
\hline To contrast & Sentence connectors & $\begin{array}{l}\text { as... as, like/alike, just like, } \\
\text { to be similar to, to be alike } \\
\text { to be similar. } \\
\text { However, in contrast, } \\
\text { Instead, in/by comparison, } \\
\text { Nevertheless, nonetheless, } \\
\text { on the other hand, on the contrary, } \\
\text { still }\end{array}$ \\
\hline
\end{tabular}


Clause connectors

Other

Sentence connectors Clause connectors

To introduce

a cause/reason

To introduce an effect/result
But, yet, although, even though, though, whereas, while.

despite (+ noun), in spite of (+ noun), compared to/with, to be different (from), to be dissimilar, to be unlike, to differ (from).

for this reason

For, because, since, as

to result from, to be the result of, due to, because of, to be the effect of, to be the consequence of, as a result of, as a consequence of

as a result, as a consequence, consequently, hence, thus, therefore

\section{The Basic Group of Transition Signals}

Oshima (1991) states that transition signals can be divided into four basic groups according to function, they are:

1. Sentence Connectors

Sentence connectors join one independent clause (Subject + Verb + Complement) with another to form a compound sentence, which is punctuated with a semicolon (;) and a comma (,). The sentence connectors used are: however, therefore, furthermore, for example, on the other hand, in addition. The pattern is:

Independent Clause ; Sentence Connector, Independent Clause

Examples: I dislike mushrooms; therefore, I never eat them.Mushrooms are good for you; however, I never eat them.

2. Coordinators

Coordinators join two independent clauses to form a compound sentence Punctuate the sentence with a comma after the first clause. The coordinators used are: and, but, yet, or, nor, for, so. The pattern is: Independent Clause, Coordinator Independent Clause

Examples: Mushrooms are good for you, but I dislike them.I dislike mushrooms, so I never eat them.

3. Subordinators

Subordinators introduce a dependent clause (subordinator + subject + verb + compliment) that joined to an independent clause to form a complex sentence. The subordinators used are: because, after, since, as, although, if, when. There are two positions for the dependent clause:

If the dependent clause comes before the independent clause, use a comma after it. The pattern is: Dependent Clause, Independent Clause Examples: Although mushrooms are good for you, I dislike them.Because I dislike mushrooms, I never eat them.If the dependent clause comes after the independent clause, do not use comma.The pattern isIndependent Clause Dependent Clause

Examples: I dislike mushrooms although they are good for you.I never eat mushrooms because I dislike them.

4. Prepositions and Determiners

This group of transition signals has no special rules for punctuation. The prepositions used are: because of, due to, in spite of.The determiners used are: another, additional, final.Examples:

I dislike mushrooms because of a bad experience I once had.Another reason I dislike mushrooms is their rubbery consistency.

\section{Kinds of Transition signals}

There are some kinds of transition signals base on its meaning or function, such as: transition signal to introduce an additional idea, transition signal to introduce an opposite idea, transition signal to introduce an example, transition signal to introduce a conclusion or summary, transition signal 
to show the signal time, etc. in this study the writer only focuses in some of transition signals for general use, they are:Oshima (1991)

1. The transition signals to indicate the signal time

\begin{tabular}{lll}
\hline 1.Immediately & 1. & Since \\
2.Thereafter & 2. & During \\
3.Formerly & 3. & At that time \\
4.Finally & 4. & Before \\
5.Meanwhile & 5. & After \\
6.Previously & 6. & Now \\
7.Then & 7. & Later \\
8. Soon & 8. & Next \\
& 9. Until \\
& 10. Afterward \\
& 11. At first, second, \\
& etc. \\
\hline
\end{tabular}

2. The transition signals to contrast. They are :
1. In contrast
2. However
3. Nevertheless
4. In spite of
5. Instead
6. On the other hand
7. Despite
8. On the contrary
9. Differing from

3. The transition signals to indicate an additional idea they are:

1. Also

2. And

3. As well

4. In addition

5. Moreover

6. Besides

7. Furthermore

4. The transition signals to comparesignals used are:
1. But
2. Yet
3. Still
4. Similar to
5. Like
6. Whereas

\section{The Short Stories}

Cliff (2018) Explained that A short story is fictional work of prose that is shorter in length than a novel. Edgar Allan Poe, in his essay "The Philosophy of Composition," said that a short story should be read in one sitting, anywhere from a half hour to two hours. In contemporary fiction, a short story can range from 1,000 to 20,000 words. Short stories also lend themselves more to experimentation — that is, using uncommon prose styles or literary devices to tell the story. Such uncommon styles or devices might get tedious, and downright annoying, in a novel, but they may work well in a short story. Another opinion,

Christine Reynier (2018) claimed that short story is defined as an art of proportion and perfection. Again, Lin Yutang (2018) discussed that "The purpose of a short story is that the reader shall come away with the satisfactory feeling that a particular insight into human character has been gained, or that his (or her) knowledge of life has been deepened, or that pity, love or sympathy for a human being is awakened.

Short stories as kind of writing of course very close in using transition signals, so that the ideas of writing can be conveyed clearly because of the ideas is tied together. From the using of transition signals dominantly, it also can help the rider to analyze the stories tell about. Short story is a kind of story shorter than the novel, characteristically developing a single central theme and limited in scope and number of characters. A short story is an invented prose narrative shorter than a novel usually dealing with a few characters and aiming at unity of effect and often concentrating on the creation of mood rather than plot Besides, short story is a work of fiction that is usually written in prose, often in narrative format. This format tends to be more longer works of fiction, such as novels or books.

\section{The Elements of Short story}

Short stories tend to be less complex than novels. Usually a short story focuses on one incident, has a single plot, a single setting, a small number of characters, and covers a short period of time. When short stories intend to convey a specific ethical or 
moral perspective, they fall into a more specific sub-category called Parables or (Fables). This specific kind of short story has been used by spiritual and religious leaders worldwide to inspire, enlighten, and educate their followers. This source was taken from the internet. There are three main elements of short stories, they are: character, plot, and setting (Oshima, 1991)

Character: A character is a person, or sometimes even an animal, who takes part in the action of a short story or other literary work. This character can be divided into some parts, some commonly are:

2. Protagonist: The driver of the action of the story and therefore responsible for achieving the story's Objective Story Goal (the surface journey). In western storytelling tradition the Protagonist is usually the Main Character.

1. Antagonist: The character that stands in opposition to the protagonist.

2. Supporting character: A character that plays a part in the plot, but is not major

3. Minor character: A character in a bit/cameo part.

4. Plot: or storyline is often listed as one of the fundamental elements of fiction. It is the rendering and ordering of the events and actions of a story. Plot also can be divided into two kinds, they are:

5. Chronological Order: All of the events occur in the order in which they happened in writing. There may be references to events from the past or future, however the events are written in time order. There will not be flashbacks/flash forwards.

6.Flashback: also called an ellipsis is an interjected scene that takes the narrative back in time from the current point the story has reached. Flashbacks are often used to recount events that happened prior to the story's primary sequence of events or to fill in crucial back story

7. Setting: is the time and place in which it happens. Authors often use descriptions of landscape, scenery, buildings, seasons or weather to provide a strong sense of setting.

Research Methodology
The research method in this study was Descriptive qualitative. Five selected short stories were analyzed in every sentence of those short stories to find what transition signals used. In order to get more information, library research was conducted to support the theories about transition signals.

\section{The Object of Research}

There were five short stories were analyzed as assumed as the object of this research. The Story Books. consisting of fourteen titles, however, only five titles of those short stories were analyzed as the representative titles, namely:

1. Tortoises

2. The Flat in Nakshabandi Street

3. After death, the Judgment

4. A citizen's Fate

5.The Exorcist of the Blue

Mountains

The Technique of collecting data

The data were collected by observingthe five short stories, then, identifying the transition signals used on each short stories.

\section{Data Analysis}

The data were analyzed by classifying the types of transition signals used in each short stories. After classifying the transition signal found in the five short stories, it was done the identification of types of each transition signals. Next, the dominant types of transition signal was identified. Finally the findings were interpreted.

\section{Findings and Discussion}

The findings and discussion in this study is the explanation of the research results of research based on the data which had been taken from library research about transition signals. In analyzing the data it is analyzed all the sentences consisting transition signals, it is also underlined the sentences of short stories which use transition signals, they are enclosed in appendices.

\section{Kinds of Transition Signals Used in Short Stories}

The analyzing result of transition signals used dominantly in short stories above can be seen by the following table: 
Table 2. The findings

\begin{tabular}{|c|c|c|c|c|c|}
\hline No. & Title of Story & $\begin{array}{c}\text { Signal } \\
\text { Time }\end{array}$ & $\begin{array}{c}\text { To } \\
\text { Contras } \\
t\end{array}$ & $\begin{array}{l}\text { Additional } \\
\text { Idea }\end{array}$ & $\begin{array}{c}\text { To } \\
\text { Compa } \\
\text { re }\end{array}$ \\
\hline 1. & Tortoises & 3 & 3 & 3 & 8 \\
\hline 2. & $\begin{array}{l}\text { The Flat in Nakshabandi } \\
\text { Street }\end{array}$ & 27 & 3 & 36 & 17 \\
\hline 3. & After Death, the Judgment & 52 & 2 & 36 & 42 \\
\hline 4. & A Citizen's Fate & 7 & 3 & 3 & 10 \\
\hline 5. & $\begin{array}{l}\text { The Exorcist of the Blue } \\
\text { Mountains }\end{array}$ & 19 & 2 & 12 & 13 \\
\hline & Total & 108 & 13 & 90 & 90 \\
\hline & $\begin{array}{l}\text { leed, in this study it is found } \\
\text { ansition signal indicates time } \\
\text { antly found in short stories. It } \\
\text { the plot in a story. Plot or }\end{array}$ & & \multicolumn{3}{|c|}{$\begin{array}{l}\text { of short stories. By counting all the } \\
\text { results, the writer found that the } \\
\text { dominant transition signal used in } \\
\text { short stories is the transition signal } \\
\text { indicating the time. }\end{array}$} \\
\hline
\end{tabular}
storyline is one of fundamental element of fiction. It is the rendering and ordering of the events of a story. Transition signal indicates time puts every event in chronological order, so that by understanding the time transition, the readers will know the arrangement of event or action happened previously.

This findings convey the message that how important to master the transition signal in writing. It covers the coherence between one topic to another to make the reader will be easier to understand the writer's expression. Specifically in writing teaching learning process, coherence from transition signal has a very important role. Due to teaching writing subject itself, it is needed to give a full attention related to transition signal that the students will be easier to express their idea to write.

\section{Conclusions and suggestions}

Having analyzed the data on the previous chapter, the writer comes to the following conclusions:

1. There are four kinds of transition signals used in the selected short stories, they are: transition signal indicting the time, indicating an additional idea, showing the comparison, and showing contrast.

2. There are different dominant transition signals used in each title

\section{The readers should study about transition signals in order to help them to use the transition signals correctly because the using of transition signals is important in writing in clarifying the ideas of writing. \\ 2. The readers should read the short stories carefully so that it can be known what the stories tell about related to the using of transition signals in developing the idea.}

\section{REFERENCES}

Barry, T, Vincent. Good Reason for Writing. Henninger: Franklin Hall.

Christine Reynier. (2018). Reviewof Woolfs essays. On line:

Cliff. (2018) The definition of short stories. On line: http://www.cliffnotes.com

Frank, Marcella. 1983. Writer's Companion. New Jersey: Prentice Hall.

G. Kriszner, Laurie., R, Mandell, S. (1985). Writing A Collage Rhetoric. UnitedStates of America: Von Hoffman Press.

G. Kriszner, Laurie., R, Mandell, S. (1989). The Holt 
Handbook.Philadelpia: Holt Rienhart and Winson Inc.

Harbrace. (1968). English Language analysis. London: The Falmer Press.

Joseph (1970).Language System Analysis.Sydney: Sydney University

Oshima,A \& Hogue, A (1991). Writing Academic English.Newjersey: Prentice hall.

Lin yutang. (2018). The purpose of short stories. On line :https//www goodreads.com

McMurrey, A, David. (1983). Writing Fundamental. New York: McMillan Publishing Co.

Morris. (1981). Educational Research.London : MPG Books Ltd. Bodmin, Cornwall
Procter.(1981). Language in interaction.London : Pinter Publishers.

Smoke, T. (1987). A Writer's Workbook. United States of America: St. Martin's Press.

Tampubolon.S (2014).Students
Ability in avoiding
Misplaced Dangling Modifier
in Writing Paragraph.Suluh
Vol. 1.(1) 2014.pp (11-19)

Tankel, Sylvia. (1989). Short Story International. United States of America:International Cultural Exchange.

Vincent (1984). Writing's building. Great Britain: Antony Rowe Ltd, Chippenham and Eastbourne. 